\title{
Arbor
}

\section{Algunas consideraciones al proceso de transición a un ejército totalmente profesional}

José Luis López Rose

Arbor CLXV, 651 (Marzo 2000), 349-369 pp.

\section{Introducción}

La necesidad de la Defensa es una realidad incuestionable. La garantía de los intereses nacionales frente a las amenazas y riesgos presumibles, los compromisos adquiridos en el marco de la seguridad colectiva, así como la voluntad de contribuir a la estabilidad y seguridad internacionales, son los elementos que deben considerarse a la hora de evaluar el volumen y características de las Fuerzas Armadas que una nación precisa.

En el caso de España, el marco conceptual de la Defensa ha cambiado substancialmente en los últimos años. Consecuentemente se han definido nuevas y diferentes misiones que requieren distintas capacidades estratégicas. Han desaparecido las amenazas tradicionales, han surgido riesgos multidireccionales y coincidiendo todo ello con un entorno sociológico que ha propiciado la desvinculación del ciudadano con los compromisos de la Defensa.

La creciente complejidad de las misiones presentes y futuras exige un mayor empleo conjunto de fuerzas terrestres, navales y aéreas. Por ello, la adopción de una decisión de tanta trascendencia como es la de modificar el modelo de Fuerzas Armadas, debe hacerse desde una óptica global, de forma que se aúnen las capacidades del conjunto de los ejércitos y que constituyan, unas respecto de las otras, factores multiplicadores. Para que el conjunto funcione a plena satisfacción es necesario que exista el adecuado equilibrio entre los tres componentes que las conforman. 
El modelo de Fuerzas Armadas del 2000 (FAS 2000), aprobado por el Parlamento en Junio de 1991, determinaba que los ejércitos, en su conjunto, deberían alcanzar en ese año una composición mixta del $50 \%$ de personal profesional y $50 \%$ de servicio obligatorio, sus efectivos totales no sobrepasarían las 180.000 personas, entre cuadros de mando y tropa, y el presupuesto de Defensa debería incrementarse progresivamente hasta alcanzar el $2 \%$ del PIB.

En cuanto al Ejército de Tierra, los efectivos de tropa deberían ascender a 88.590, de los cuales solo 26.500 habrían de ser profesionales, por lo que la tasa de profesionalización a alcanzar sería del $30 \%$. Con esos parámetros se iniciaron los estudios para estructurar un nuevo Ejército, que se concretó en el Plan NORTE.

En la actualidad, la implantación del Plan NORTE ha finalizado prácticamente. Con él se inició una etapa de cambios trascendentales, puesto que su objetivo fundamental era transformar un Ejército de carácter territorial en otro estructurado en función de las misiones a cumplir y con gran capacidad de proyección; en definitiva, se ha diseñado un Ejército de Tierra que responde a los requerimientos operativos terrestres que la defensa de España demandará en el futuro previsible. La modernización del armamento y material, contemplada en ese Plan y que por razones presupuestarias se ha venido posponiendo año tras año, junto con la plena participación en la Alianza Atlántica y la total profesionalización de sus hombres y mujeres, decididas por el Gobierno con posterioridad a la elaboración del Plan NORTE, son los restantes grandes retos a los que el Ejército está haciendo frente.

La estructura nacida del Plan NORTE, concebida como se ha dicho con perspectiva de futuro, apuesta claramente por la acción conjunta de forma que la Fuerza Terrestre prevista se considera la mínima que España necesita, tanto para el cumplimiento de las misiones exteriores en las que el Gobierno considere oportuno participar, como para ser oída en los foros internacionales y, por supuesto, para asegurar los intereses españoles frente a los riesgos que tendremos que afrontar en solitario. El factor económico de ineludible consideración al limitar la disponibilidad de recursos de todo tipo, junto con los requerimientos operativos antes expuestos, fueron determinantes a la hora de dimensionar las plantillas de efectivos de las Unidades.

Conviene recordar que la decisión de acometer la plena profesionalización de las FAS es una iniciativa de tipo político y no militar, con la que se pretendió dar respuesta a la creciente desvinculación de la sociedad española con el Servicio Militar Obligatorio. Es por tanto un problema de origen sociológico el que ha impulsado a tomar 


\section{Algunas consideraciones al proceso de transición}

esta decisión ahora, aunque es evidente que el Ejército de Tierra precisaría en el futuro inmediato de mayores niveles de profesionalización de los que el modelo FAS 2000 determinaba.

La multiplicidad y disparidad de misiones encomendadas al Ejército, los diferentes ambientes en que se pueden desarrollar, así como la avanzada tecnología de los materiales demandan un soldado con un perfil que difiere notablemente del soldado actual. El soldado del futuro debe ser capaz de realizar eficazmente una amplia gama de actividades, desde el combate integrado en Unidades multinacionales hasta las operaciones humanitarias y de apoyo a la paz, pasando por el apoyo a la población en situaciones de catástrofe. Esto comporta el tener una excelente preparación física y fundamentalmente psíquica y moral, y además poseer unos conocimientos técnicos muy superiores a los que se venían necesitando. Todo ello nos conduce a afirmar que el soldado del futuro debe ser sin duda profesional, ya que los períodos de adiestramiento superarán con mucho los plazos que cualquier Servicio Militar Obligatorio pudiera permitir.

Procede hacer una consideración en relación con el término "profesional». La interpretación que debe de darse a ese término no es la que se refiere solo al carácter de la relación de servicios que sus componentes guarden con los ejércitos, sino la más amplia, del nivel deseado de competencia, que en su conjunto deben alcanzar todas las Unidades para cumplir con eficiencia sus misiones. El Ejército del futuro, que ahora se está concibiendo, demanda no sólo soldados profesionales sino dotaciones de materiales acordes con lo que se les va exigir. La eficacia está íntimamente relacionada con las características del armamento y material. Es necesaria una perfecta integración entre la técnica más avanzada y el soldado profesional bien instruido.

En cuanto a la modernización de los materiales debe significarse que la profesionalización, en sí misma, no implica modernización. La modernización es una necesidad permanente de los Ejércitos, a través de la cual deben incorporar, de forma razonable, cualquier avance tecnológico que mejore la eficacia de sus actividades. De ahí que la profesionalización sea una parte de la modernización por lo que ambos conceptos son inseparables; profesionalización sin modernización no tiene sentido.

Por todo ello, en el proceso de profesionalización deben distinguirse dos etapas: una de transición de un ejército mixto a otro profesional, y otra de evolución de un ejército del siglo XX a otro del siglo XXI. La primera es crítica y la forma en que se realice determinará en gran medida el éxito o el fracaso del nuevo modelo. 
Por otra parte, ese proceso debe contemplarse desde dos ópticas diferentes: una externa al Ejército de Tierra, que compete al poder político como responsable de la obtención de los recursos humanos que las FAS precisan, y en la que debe colaborar al máximo; y otra interna, que se deriva de las características propias del nuevo soldado, e implica la adopción de medidas muy diversas relacionadas con los programas de instrucción y adiestramiento, la adaptación al nuevo modelo de las infraestructuras, la adecuación a las actuales necesidades de los sistemas de gestión del personal, la modificación de procedimientos $\mathrm{y}$ reglamentos, etc.

En este artículo se trata de analizar, desde el punto de vista del recurso humano, y particularmente de la tropa, las implicaciones que para el Ejército tiene el proceso de plena profesionalización que se ha iniciado, sin pretender agotar todas las facetas que en un programa tan ambicioso como el que se inicia deben ser tenidos en cuenta.

En este sentido, conviene recordar que el índice de profesionalización que el modelo FAS 2000 determinaba para el Ejército de Tierra era notablemente inferior a los previstos entonces para la Armada y el Ejército del Aire. Al establecer que el $100 \%$ de los miembros de las FAS. sean profesionales parece claro que las necesidades anuales de soldados profesionales en el Ejército de Tierra son muy superiores a las de los otros dos Ejércitos, no sólo porcentualmente sino sobre todo en términos absolutos.

\section{Implicaciones del nuevo modelo en relación con el personal de tropa}

Una vez adoptada la decisión política de sustituir el actual modelo mixto por otro plenamente profesional, deben adoptarse las medidas oportunas para asegurar, dentro de lo posible, que los ejércitos dispongan de los efectivos que el Planeamiento de la Defensa Militar determine como necesarios, tanto en cantidad como en calidad. Partiendo de la base de que, hoy por hoy, no existen, ni se esperan, problemas de importancia para garantizar que las FAS cuenten con el número de cuadros de mandos que sus plantillas demandan, se tratarán esos aspectos en cuanto se refiere con la tropa profesional.

Tres aspectos, que se corresponden con «el antes, durante y después de ser soldado», deben considerarse y tratarse de forma conjunta por cuanto cada uno de ellos repercute de forma muy importante en los 


\section{Algunas consideraciones al proceso de transición}

otros: el Reclutamiento, la Selección y Formación, y la Reincorporación a la vida civil del soldado una vez finalice su servicio activo.

Antes de abordarlos recordemos las características más relevantes del modelo en relación con la tropa y marinería:

1) Los efectivos máximos de tropa y marinería no superarán los 120.000 hombres y mujeres, que se corresponden con los que los Cuarteles Generales y el Estado Mayor de la Defensa han cuantificado como necesarios en función de los requerimientos operativos.

2) Todos los efectivos de tropa y marinería serán profesionales; unos mantendrán con las Fuerzas Armadas una relación de servicios de carácter temporal con compromisos renovables de 2 ó 3 años hasta un máximo de 12 años de servicio o 35 años de edad, y otros mantendrán una relación de carácter permanente.

3) Todos los ciudadanos, hombres y mujeres, podrán ejercer el derecho constitucional de participar en la defensa de España, mediante una permanencia en las FAS de corta duración (12 ó 18 meses) remunerada. Una vez finalizado este período podrán optar por continuar en los Ejércitos con compromisos renovables de 2 o 3 años, o bien finalizar su servicio activo. También podrán ejercer ese derecho accediendo a las plazas que se oferten para reservistas voluntarios.

4) Se impulsará la promoción interna de manera que se facilite al máximo posible el acceso a las escalas de Suboficiales, de Oficiales y Superior de Oficiales. Todas las plazas para las escalas de Suboficiales se reservarán para el personal profesional de Tropa y Marinería.

\subsection{Reclutamiento}

El reclutamiento es sin duda el aspecto clave. Para cubrir las necesidades de personal de los Ejércitos el Ministerio de Defensa debe competir abiertamente en el mercado de trabajo, lo que le obliga a incrementar los atractivos de la profesión militar, de forma que proporcione contraprestaciones similares, o incluso superiores, a las que se ofrecen en el mundo laboral.

De acuerdo con la encuesta realizada por el Centro de Investigaciones Sociológicas a principios de 1997, uno de cada cinco jóvenes manifiesta que en algún momento podría decantarse por la opción de ingresar en las FAS como tropa y marinería profesional por alguna de las siguientes razones:

- Cobrar un sueldo. 
- Facilidad para acceder a militar de carrera por promoción interna.

- Mejores posibilidades para conseguir un puesto de trabajo en la vida civil cuando finalice su compromiso con las FAS.

- Espíritu de aventura.

- Vocación militar.

Los jóvenes que acceden a los Centros de Formación de Militares de Tropa y Marinería Profesional al ser interrogados sobre los motivos que le indujeron a ingresar como soldado profesional manifiestan esas mismas razones. Es lógico pensar que gran parte de ellos participará en mayor o menor grado de muchas o de todas esas razones, predominando una u otra según la persona.

Por otra parte, encuestas realizadas a Militares de Tropa Profesional coinciden también con las anteriores en los motivos que inducen a nuestros soldados a renovar sus compromisos, si bien varía notablemente el orden en las preferencias, de forma que puede afirmarse que el interés por hacer de la milicia su profesión definitiva, ya sea como militar de carrera por la vía de la promoción interna o bien como tropa profesional permanente, aumenta conforme a los años de servicio. No obstante, los soldados profesionales manifiestan que existen otros aspectos incentivadores para un mejor reclutamiento y una permanencia más prolongada en las Fuerzas Armadas que deben mejorarse. Entre ellos destacan:

- Prestigiar la profesión militar ante la sociedad.

- Mejorar la calidad de vida del soldado.

En consecuencia, aquellos y éstos son los campos en los que hay que actuar para fomentar el acceso de los jóvenes, hombres y mujeres, a las FAS.

Vocación y prestigio

La sociedad se encuentra sometida a un proceso de cambios continuos; predominan ahora los valores individuales frente a los colectivos, y determinados principios, como el de autoridad y disciplina, han perdido arraigo. El bajo nivel de conciencia de la opinión pública española en relación con la importancia y necesidad de la Defensa, la percepción generalizada en nuestra sociedad de la inexistencia de amenazas y riesgos para nuestra seguridad, y el poco «gancho» que tiene la profesión militar, no estimulan a priori a los jóvenes españoles a decantarse por el «oficio de soldado». 


\section{Algunas consideraciones al proceso de transición}

Además, el carácter confidencial que tienen muchos asuntos relacionados con las cuestiones de la Defensa Nacional, dificulta el que la sociedad conozca y forme su propia opinión sobre la necesidad de disponer de unas Fuerzas Armadas acordes con el peso específico que España puede y debe tener en el concierto internacional. Todo ello dificulta notablemente el reclutamiento.

La participación de nuestras Unidades en misiones de paz y de ayuda humanitaria en el exterior, y la eficacia y profesionalidad internacionalmente reconocidas con que han cumplido sus cometidos, han mejorado notablemente la imagen de las FAS. en la sociedad. Sin embargo, incidentes aislados, que son ampliamente divulgados por los medios, dañan de forma muy importante la imagen de los ejércitos y, particularmente, de sus profesionales lo que, sin duda, detrae a posibles aspirantes.

El Ejército ha hecho un esfuerzo muy importante, a costa de sacrificios personales, para adaptar su estructura a los nuevos tiempos. Esa estructura será ineficaz si no se consigue dotarla del personal adecuado. Es preciso una revolución de mentalidades para poner en sintonía a quienes sirven en los Ejércitos con lo que la sociedad demanda de ellos.

Las características del soldado profesional, que se resumen en mayor espíritu crítico y conciencia de sus derechos y deberes, carácter más especializado y técnico, con mayores responsabilidades sociales, y con legítimas aspiraciones profesionales y expectativas de futuro, exigen un tipo de relaciones diferente al del Militar de Reemplazo. «El nuevo estilo de mando", que a modo de decálogo promulgó el GE. JEME en Octubre de 1997, es el resultado de una iniciativa que el propio Ejército de Tierra impulsó en su seno para adecuar los principios del liderazgo en nuestras Unidades a las circunstancias actuales y a las que se presentarán en el futuro previsible.

La motivación del personal femenino adquiere ahora especial relevancia pues debe potenciarse el papel de la mujer en las FAS. La igualdad de oportunidades, de responsabilidades y de funciones en los Ejércitos, entre hombres y mujeres, son los aspectos en este sentido deben destacarse para fomentar el alistamiento de la mujer.

\section{Retribuciones}

El sueldo que actualmente percibe el soldado profesional está comprendido entre las 100.000 y las 160.000 ptas. aproximadamente. En relación con el que devengan los soldados profesionales de otros países 
europeos, una vez corregidos por los índices correspondientes de carestía de vida, y comparado con el salario mínimo interprofesional español, se considera adecuado. Por otro lado, no puede olvidarse que el límite máximo de retribuciones de la tropa debe estar siempre condicionado por tener que ser inferior al de los suboficiales. Sin embargo, hay cuestiones pendientes en cuanto a retribuciones, que requieren una pronta solución.

En unos ejércitos plenamente profesionales no caben diferencias en conceptos retributivos entre empleos que cubren puestos de trabajo de características similares. Determinados complementos, que priman la mayor peligrosidad o penosidad de destinos en determinadas Unidades o puestos (montaña, paracaidismo, operaciones especiales, etc.), deben hacerse extensivos a toda la tropa y marinería. La ausencia de diferencias incluye también el que los soldados acumulen trienios, cosa que ahora sólo sucede con aquellos que tienen reconocido el derecho a permanecer en las FAS. hasta la edad de retiro. Deberían también contemplarse, en los presupuestos, aquellos devengos correspondientes a dietas, pluses e indemnizaciones por comisiones, traslados, maniobras, etc., si se quieren alcanzar los niveles deseables de adiestramiento y respetar las retribuciones reconocidas a las privaciones, sacrificios y molestias sociales y familiares que la vida militar implica.

Por otra parte, no debe obviarse la posibilidad de tener que primar económicamente destinos en determinadas Unidades de características singulares donde podría existir el riesgo cierto de que no se cubran voluntariamente los puestos que se oferten. Si en la actualidad los Militares de Reemplazo cobran determinadas gratificaciones por ir destinados a esas Unidades, no hay razón para que no se actúe de la misma forma con los profesionales.

\section{Calidad de vida}

La mejora de las condiciones de vida en los cuarteles es el primer punto a considerar en este sentido. Nuestras bases y acuartelamientos no fueron diseñados para alojar a un ejército profesional y tienen que ser acondicionados a las nuevas necesidades con carácter urgente. Los alojamientos para la tropa que, fuera de las horas de trabajo y servicio, viva habitualmente en las Bases y Acuartelamientos deben proporcionar niveles de intimidad y confortabilidad suficientes.

Además, la distribución horizontal de la mayoría de los cuarteles, en los que no existe una clara separación entre zonas de «vida» y de 


\section{Algunas consideraciones al proceso de transición}

«trabajo», así como los medios disponibles para vigilancia, demandan una importante cantidad de recursos humanos en misiones de seguridad que hay que detraer de otras actividades. El Ejército del futuro, minorado en recursos humanos, con materiales de elevado coste que deben ser rigurosamente entretenidos y mantenidos, con programas de instrucción y adiestramiento más complejos e intensivos, no puede permitirse el lujo de dedicar diariamente un buen número de hombres y mujeres para esos cometidos. El Ejército no sólo debe ser eficaz, sino eficiente. Para ello, se precisan fuertes inversiones que, si no aumentan los presupuestos, habrá que derivar forzosamente de alguna otra partida.

Aunque la cobertura del ISFAS. y la Acción Social en el Ejército de Tierra alcanza a toda la tropa y sus familiares dependientes, sin distinción de empleos ni años de servicio, existen ciertas cuestiones relativas a prestaciones sociales aún no del todo resueltas.

La actual Ley de apoyo a la movilidad de los miembros de las FAS. establece 5 años como tiempo mínimo de servicios efectivos a partir del cual se tendrá derecho a percibir la correspondiente contraprestación económica durante un máximo tres años en un mismo destino; así mismo, el derecho a disfrutar de vivienda militar, mediante arrendamiento especial, se tendrá solamente con ocasión de una vinculación de carácter permanente.

También se debe potenciar la disponibilidad de residencias y centros de descanso y ocio para la tropa y marinería profesional. La movilidad que justifica estas instalaciones afectará por igual a todos los empleos de la jerarquía militar.

Por último, es fundamental que se mantenga, tal y como está previsto, el derecho a devengar la prestación por desempleo de aquellos que al finalizar su compromiso con las FAS. no consigan un puesto de trabajo.

\section{Expectativas de trayectoria profesional}

Tras unos años de permanencia en las Fuerzas Armadas, los soldados profesionales sienten una lógica preocupación por su futuro y, en muchos casos, manifiestan su deseo de permanecer en los ejércitos durante toda su vida activa. Según las previsiones actuales sólo una minoría de los ingresos anuales una vez que se consolide el modelo, que cabe cifrar en torno a un $10 \%$ ó $20 \%$, podrá permanecer como Tropa y Marinería en las Fuerzas Armadas hasta la edad de retiro. 
El soldado con una relación de servicios de carácter temporal podrá, mediante la renovación de sucesivos compromisos, prestar servicio en los Ejércitos hasta un máximo de 12 años de servicios ó 35 años de edad. A partir del octavo año de servicio podrá optar a la condición de tropa permanente mediante concurso-oposición, pudiendo concurrir hasta un máximo de tres convocatorias. Por lo tanto, deben determinarse qué puestos deben ser cubiertos en exclusividad por Tropa Permanente; en éstos, lógicamente, la condición física no debe ser un factor determinante. Muchos de estos puestos se encontrarán en Unidades del Apoyo a la Fuerza, en los Cuarteles Generales y en la Organización Territorial, sin descartar que en todas y cada una de las UCO,s. exista un número determinado de vacantes para Tropa Permanente.

En cuanto a política de empleos y ascensos se han reconsiderado los empleos para dar una mayor proyección de carrera a la tropa profesional. Para ello se ha creado el nuevo empleo de Cabo Mayor, el de mayor rango en la categoría de Tropa, al que se podrá acceder tras el correspondiente curso con las siguientes condiciones: tener cumplidos más de tres años en el empleo de Cabo $1^{\circ}$ y acumular al menos tres años como Tropa Permanente.

\section{Promoción interna}

La promoción interna es uno de los mayores alicientes de los posibles aspirantes a tropa y marinería profesional y una pretensión de los actuales Militares de Tropa Profesional por lo que debe prestársele una especial atención y así se hace en la nueva Ley del Régimen del Personal Militar de las FAS. Constituye, junto con la adquisición de la condición de Tropa Permanente y el acceso a la Guardia Civil, la «salida natural» de la tropa con una relación de servicios de carácter no permanente.

En la nueva Ley, se ha decidido "abrir la puerta» a la promoción interna, a los empleos inferiores de tropa, con la exigencia de acreditar tres años de servicio en las Fuerzas Armadas. Con ello se consiguen dos objetivos: reducir la edad de adquisición de la condición de militar de carrera en las Escalas de Suboficiales del personal procedente de tropa profesional, y motivar en mayor medida a los jóvenes. Si se mantienen las estadísticas actuales relativas a niveles académicos de los aspirantes a soldado profesional, el aumento de opositores que esa medida originará proporciona suficientes garantías para que puedan 


\section{Algunas consideraciones al proceso de transición}

cubrirse mediante promoción interna el $100 \%$ de las plazas que anualmente se convoquen.

\section{Otras expectativas}

El elevado índice de paro es un factor que sin duda favorece el reclutamiento, ya que hay quienes buscan en las FAS. una solución transitoria a su problema laboral con la esperanza de conseguir una capacitación que les proporcione mayores posibilidades de acceder a un puesto de trabajo. Prueba de ello es que los jóvenes argumentan como dos de las razones prioritarias para decantarse por el ingreso en las FAS, el sueldo y la mayor posibilidad de encontrar un puesto de trabajo.

El número de soldados que ingresan en cada convocatoria y que pueden permanecer en las FAS., bien como cuadros de mando por la vía de la promoción interna, bien como tropa profesional permanente, o ingresar en la Guardia Civil, vendrá determinado por las correspondientes plantillas. De aquí se deduce la trascendencia de arbitrar medidas para que aquellos que voluntaria o forzosamente abandonen los ejércitos tengan facilidades para acceder a un puesto de trabajo; si no se consigue el éxito en este empeño, y a pesar de una favorable evolución del reclutamiento, el modelo a medio plazo podría fracasar. Es de gran importancia que la sociedad reconozca y valore el "valor añadido" que se le da al soldado durante su permanencia en filas, que incluye no sólo las aptitudes y conocimientos que el Ejército le proporciona, sino fundamentalmente las actitudes, comportamientos y hábitos que la persona adquiere.

\section{Captación}

El reclutamiento, es decir, el captar personal suficiente en cantidad y calidad, determinará el éxito o fracaso del modelo, por lo que es el objetivo fundamental que impulsa la mayoría de las acciones dirigidas al «antes» $y$ «después» del soldado.

De acuerdo con las previsiones actuales, el número de nuevos soldados que deberán ingresar anualmente en las FAS durante el período de transición al nuevo modelo (hasta el 31 de diciembre del 2002) podrá superar las 25.000. Esta cifra incluye, no sólo a los incrementos precisos para aumentar la tasa de profesionalización al ritmo previsto, 
sino también a los necesarios para reponer las bajas de aquellos que no renueven su compromiso.

En la situación actual, de limitadas posibilidades demográficas y sin consolidar el nuevo modelo, acortar los plazos para alcanzar la plena profesionalización originaría un serio perjuicio. La prisa en este caso no es buena consejera.

Reclutar, en su acepción extensa ofrecida por la Real Academia Española de la Lengua, significa buscar o allegar adeptos para un propósito determinado; uno de los grandes retos al que se enfrenta el Ejército de Tierra es el tener que adoptar una postura activa de búsqueda de aspirantes a soldado. Ello exige también un cambio de mentalidad en los cuadros de mando.

Además de ofrecer a las personas que accedan al Ejército buenas perspectivas temporales, y en algunos casos permanentes, que les atraiga hacia esta profesión, deben impulsarse las campañas de información y propaganda, modificar los sistemas y procedimientos de reclutamiento y selección de aspirantes para hacerlos más flexibles y dinámicos, y adecuar los programas de formación, instrucción y adiestramiento a las peculiaridades y expectativas del nuevo soldado.

Campañas de información y propaganda

A medida que avanza el período de transición hacia las FAS totalmente profesionales, con una progresiva disminución del contingente procedente del Servicio Militar Obligatorio y unas previsiones demográficas desfavorables, cobran especial relevancia las campañas de propaganda e información.

La época actual se conoce, como es sabido, por la Era de la Comunicación. Los avances espectaculares experimentados en los medios y técnicas de información y comunicación deben utilizarse como medio para hacer llegar a los españoles, hombres y mujeres en edad de poder aspirar a un puesto en las FAS, los mensajes más adecuados para que conozcan su realidad y aprecien los aspectos positivos de su incorporación al Ejército. Eștos mensajes deberán basarse fundamentalmente en los factores de motivación y en los incentivos antes expuestos.

Además del factor demográfico (número de jóvenes en edad de alistarse en cada región), sin duda determinante en la materia, cobran especial importancia a la hora de diseñar estas campañas los siguientes aspectos:

a) Las preferencias mostradas por los aspirantes para cubrir determinadas especialidades en Unidades que le son más atractivas. 


\section{Algunas consideraciones al proceso de transición}

b) La presencia de Unidades que ofertan plazas en su zona de residencia. Este factor influye en un doble sentido: por la posibilidad de trabajar cerca de su domicilio y por el atractivo que la presencia cercana y habitual de militares genera en los años cruciales de la infancia y juventud.

c) La tasa de paro juvenil en cada región.

d) El nivel socioeconómico del aspirante.

e) El grado de identificación de la sociedad con la Institución militar.

Por ello, las campañas de propaganda, en función de las disponibilidades presupuestarias, deben programarse y ejecutarse de manera selectiva, según épocas y zonas. Además de aquellas dirigidas al conjunto de la sociedad (campañas institucionales), deben diseñarse otras dirigidas específicamente a los jóvenes en edad de alistarse (campañas promocionales). En todo caso, las campañas deberían cumplir una serie de condiciones:

- Ir dirigidas hacia jóvenes que quieran hacer de la profesión militar su medio de vida, hacia los que les anima el espíritu de aventura, y hacia aquellos otros que buscan exclusivamente un empleo.

- Introducir factores de concienciación sobre la necesidad de la Defensa y de participación activa como medio de contribución a la misma, evitando el desarraigo y el desinterés por parte de la sociedad.

- Diseñarse con un sentido de transparencia total, evitando despertar falsas expectativas para evitar la posterior frustración y antipropaganda.

- No dar una imagen frívola de la profesión, sino resaltar lo que conlleva de solidaridad., entrega y sacrificio.

- Lanzarse de forma constante y regular para asegurar el alistamiento continuo.

Pero la labor de captación de futuros profesionales de tropa y marinería no puede limitarse a la propaganda a través de los medios de comunicación; es imprescindible ir más lejos, acercándose directamente a quienes están o pueden estar en un plazo relativamente breve en condiciones de acceder a las FAS. Es decir, debe propiciarse el contacto personal con los jóvenes de ambos sexos.

Para ello se están realizando cursos específicos de Equipos de Captadores que se desplazan a los Centros de Reclutamiento en épocas de admisión de instancias para cada Incorporación, a las propias Uni- 
dades con Militares de Reemplazo, a ferias de empleo o exposiciones dirigidas a la juventud, y cuando así lo soliciten a organismos públicos donde se concentre la juventud, con la finalidad de proporcionar a los jóvenes interesados información directa y personalizada sobre la vida en el Ejército, peculiaridades de cada Unidad y especialidad, expectativas profesionales, y cualquier otro asunto de su interés.

Además, deberá conseguirse que cualquier joven pueda obtener información puntual, personalizada y, en su caso, cumplimentar la solicitud de inscripción, en cualquier Base o Acuartelamiento próximo a su domicilio, evitando, siempre que fuera posible, incómodos desplazamientos al Centro de Reclutamiento en la capital de su provincia. Con este fin, deben potenciarse las Oficinas de. Información al Soldado que ya existen. En una palabra, el sistema debe acercarse al individuo y no el individuo al sistema.

Como complemento de todo lo anterior, es muy oportuno el potenciar las jornadas de «puertas abiertas» para que la sociedad pueda profundizar en el conocimiento de sus Ejércitos.

Sin embargo, hay que ser consciente que la mejor y la peor, en su caso, propaganda es la que realiza el soldado en su entorno inmediato. Su satisfacción o frustración será lo que facilite o reste futuros aspirantes a soldado.

\subsection{Selección y formación}

En la actualidad, el proceso selectivo del aspirante a soldado profesional consta de dos fases:

1. ${ }^{\text {a }}$ Se desarrolla en los Centros de Reclutamiento donde los solicitantes realizan la prueba de evaluación personalizada.

$2 .^{\text {a }}$ Se lleva a cabo en los Centros de Formación donde los aspirantes preseleccionados pasan un reconocimiento médico, una prueba de personalidad y otras de aptitud física.

Este procedimiento debe mejorarse pues tiene una duración dilatada durante la cual se produce un goteo constante de bajas. El Órgano Central de Ministerio de Defensa, con la colaboración de los tres Cuarteles Generales, está diseñando un nuevo sistema que dé mayor rapidez y continuidad al proceso selectivo, al tiempo que posibilite seleccionar a los mejores en función de las aptitudes del aspirante y de las características de los puestos a cubrir.

Por otra parte, la formación del soldado profesional se realiza en dos fases: una de formación general militar, que es común para todas 


\section{Algunas consideraciones al proceso de transición}

las especialidades, y otra complementaria o especifica que difiere según la especialidad de que se trate. La primera se realiza en un período de 10 semanas, y la segunda tiene una duración variable en función de la especialidad, (entre las dos fases la duración será de 3 meses a 1 año).

Con el fin de facilitar la reincorporación al mercado laboral del soldado cuando finaliza su permanencia en las Unidades, el Ejército de Tierra ha propiciado el que la Tropa Profesional obtenga, al finalizar su formación, una titulación reconocida por el MEC. Por eso, los programas de formación específica de los soldados especialistas se ajustan a los correspondientes de la LOGSE., y se aumentan en los créditos correspondientes a las materias específicas militares. Además, existe un manifiesto interés en que aquellas aptitudes que tienen aplicación en la vida civil (operadores de máquinas pesadãs, telecomunicaciones, seguridad, buceadores, topografía, etc.), y que la tropa obtiene tras la realización de determinados cursos, tengan reconocida su validez oficial.

Por último, los programas de instrucción y adiestramiento de las Unidades que actualmente son repetitivos, puesto que se diseñaron pensando más en el Militar de Reemplazo que en el profesional, están siendo modificados. Los nuevos programas se están diseñando de forma que un soldado profesional desarrolla un ciclo completo de instrucción y adiestramiento en un período aproximado de dos años.

\subsection{La finalización del compromiso}

La finalización del compromiso que vincula a los soldados con el Ejército, con independencia de la causa que la motive, en la medida en que supone la total extinción de los derechos y obligaciones recíprocos, es una cuestión de capital interés en el marco de los problemas que plantea la plena profesionalización.

Existe la necesidad de ofrecer a los soldados profesionales cuantas posibilidades puedan encontrarse, acordes con el ordenamiento jurídico, para facilitar su retorno a la vida civil y al mercado laboral, hasta el punto que el éxito en el reclutamiento, como se dijo, depende del logro de este objetivo.

Confluyen en esta cuestión tanto el interés de las Fuerzas Armadas como el de los soldados y marineros profesionales. El de los Ejércitos porque con ello, además de facilitar la captación de aspirantes, pueden conseguir una mínima permanencia en filas del soldado, en función 
de los tiempos de servicio que se exijan para alcanzar aquella preparación o para acceder a las ventajas que se establezcan. El de los propios soldados profesionales porque, a los valores adquiridos fruto de su formación militar que le pueden ser rentables en el plano laboral, añadirán la formación y preparación extramilitar que reciban, orientada a las posibilidades de obtención de empleo.

Prueba de la importancia de esta cuestión es la preocupación que los problemas vinculados a la finalización del compromiso ha venido suscitando desde el momento mismo en que la anterior Ley 17/1989, de 19 de julio, reguladora del Régimen del Personal Militar Profesional instituyó la figura del militar de empleo de tropa y marinería profesional.

Problemas de orden jurídico, pues una política de la que pueda derivarse una discriminación positiva ventajosa para soldados y marineros profesionales, podría chocar con el principio constitucional de igualdad consagrado en los artículos 14 y 23.2 de la Constitución.

Otros de carácter social, pues ese posible efecto discriminatorio positivo puede suscitar la oposición de organizaciones sindicales y profesionales cuyos intereses puedan verse más directamente afectados, y por los sectores de la sociedad con mayores dificultades en el acceso al empleo.

Por último, esos problemas pueden también tener su reflejo en las relaciones de colaboración y coordinación entre el Ministerio de Defensa con los demás Departamentos Ministeriales que intervienen en la política de promoción y, particularmente, con las Administraciones Públicas distintas de la Administración General del Estado.

En consecuencia, parece claro que más que un replanteamiento de la medidas de promoción del soldado para el momento de finalización de su compromiso, lo que procede es avanzar en las existentes, buscando en todo momento el máximo rendimiento que pueda obtenerse dentro de las limitaciones inherentes a los problemas a que antes se hizo mención.

\section{Formación Profesional y Ocupacional}

En los dos subsistemas en que se diversifica el régimen de Formación Profesional, el relativo a la Formación Profesional Reglada, objeto de la LOGSE, y el referido a la Formación Profesional Ocupacional, cuyo objeto es desarrollar el Plan Nacional de Formación e Inserción Profesional, los acuerdos y convenios suscritos por el Ministerio de Defensa, 


\section{Algunas consideraciones al proceso de transición}

respectivamente, con el Ministerio de Educación y Ciencia y con el Ministerio de Trabajo y Asuntos Sociales, así como, en ambos casos, con las Consejerías competentes de las Comunidades Autónomas a las que han sido transferidas las competencias en la materia, los problemas a que podría dar lugar la plena profesionalización de las FAS están resueltos desde una óptica formal.

Por consiguiente, lo único que aquí cabe preguntarse es si el número de cursos y plazas que se ofertan anualmente son suficientes. Cada año se realizan por término medio 300 cursos Formación Profesional Ocupacional, en los que participan en torno a las cien unidades militares. En el período 1988/1997, 13.588 alumnos (entre soldados de reemplazo y tropa y marinería profesional) participaron en las pruebas de enseñanzas no escolarizadas (FP-1) para acceder al título de Técnico Auxiliar, habiéndolo obtenido 5.770 .

El esfuerzo que se realiza en este campo debería aumentar, para lo que es preciso mayores asignaciones presupuestarias. Complementariamente, a nivel regional se deben fomentar los contactos con empresas y agencias para que el personal en filas disponga de información directa sobre las posibilidades del mercado de trabajo y se faciliten las relaciones del personal cuyo compromiso esté próximo a finalizar con los oferentes de empleo. La experiencia que en este sentido se ha adquirido, tanto en cuanto a militares de reemplazo se refiere como a tropa profesional, es altamente satisfactoria.

La oferta pública de empleo

De naturaleza distinta y más compleja son los problemas que puede ocasionar la incidencia de la política de promoción sobre la oferta pública de empleo.

La determinación de reservar al menos el cincuenta por ciento de las plazas de acceso al Cuerpo de la Guardia Civil, para la tropa y marinería profesionales que cumpla los requisitos establecidos, configura una modalidad de "promoción interna» atípica. Esa reserva se contempla en la Ley del Régimen del Personal Militar Profesional como un criterio numérico mínimo, por lo que cabe la posibilidad que aumente en el futuro. Con la finalidad de preparar a quienes voluntariamente quieran concursar en estas convocatorias, se han constituido, con gran éxito, academias preparatorias en las Unidades, subvencionadas por el Ministerio de Defensa. 
Además, la Ley determina que se considerará como mérito el tiempo de servicios en las Fuerzas Armadas en los sistemas de selección para las plazas de funcionario y actividades de carácter laboral de las Administraciones Públicas, en todos los supuestos en que sus funciones guarden relación con los servicios prestados o aptitudes y titulaciones adquiridas. En el caso concreto de las convocatorias para el acceso a Cuerpos o Escalas adscritos al Ministerio de Defensa y para el ingreso como personal laboral en este Departamento y sus organismos autónomos, se reservarán igualmente, al menos un 50\% de plazas para los militares profesionales que hayan cumplido un mínimo de tres años de servicios.

El acceso de la tropa profesional a los Cuerpos de Policía Autonómicos lo vemos más problemático porque, del propio principio autonómico, se deriva la capacidad de las Comunidades Autónomas para organizar sus propios servicios. Por consiguiente, no cabe más que esperar la voluntaria colaboración de las Comunidades Autónomas que tienen constituidos Cuerpos de Policía propios, para conseguir los objetivos que se persiguen.

Los tres años previstos para participar en el procedimiento de acceso a las plazas reservadas, tanto en el Cuerpo de la Guardia Civil como en el propio Ministerio de Defensa y sus organismos autónomos, se considera razonable porque permite que el soldado, una vez finalizado un ciclo completo de instrucción y adiestramiento, pueda preparar su futuro al tiempo que el Estado ha rentabilizado la inversión realizada en su formación.

\section{Formación Específica de Doble Uso}

Algunas de las especialidades desarrolladas por los soldados y marineros profesionales durante su permanencia en las Fuerzas Armadas, pueden ser ejercidas por éstos en la vida civil con total competencia y garantía. Asimismo, hay otras especialidades que sin ser idénticas tienen campos de actividad comunes con profesiones existentes en el ámbito laboral. Sin embargo, esta preparación y capacidad para desempeñar una profesión $u$ oficio en el mercado de trabajo no es reconocida con frecuencia en su verdadero valor debido a la ausencia de una titulación oficial. De ahí el empeño en obtener titulaciones convalidables o reconocidas.

El reconocimiento de estos conocimientos adquiridos y practicados, unido a la garantía que deben ofrecer los informes personales regla- 


\section{Algunas consideraciones al proceso de transición}

mentarios sobre experiencias acumuladas y actitudes demostradas, deben ser adecuadamente valorados por los empresarios.

Finalmente y como es obvio, cualquier medida y acción que se emprenda debe hacerse sin menoscabo de la operatividad de las unidades, pues no debemos olvidar que los soldados a quienes van dirigidas son profesionales necesarios para que el Ejército mantenga los niveles deseables de operatividad.

\section{Otras implicaciones}

\section{Reserva Movilizable}

Una de las razones principales en favor de la total profesionalización de nuestras Fuerzas Armadas es la creciente demanda social hacia este modelo, acorde con los tiempos actuales en que la especialización se extiende a todos los ámbitos. En consecuencia, se aboga porque la defensa nacional recaiga también sobre profesionales.

Sin embargo, y como contraposición la sociedad también debe admitir y ser consciente de que, en caso de necesidad, debe contribuir aportando el personal necesario para alcanzar y mantener el volumen de fuerza requerido.

La Ley Básica de Movilización 50/69, resulta obsoleta ya que, fundamentalmente, esta dirigida a conseguir la movilización general de la nación para hacer frente a situaciones extremas, circunstancia ésta hoy día improbable.

Una vez establecida la plena profesionalización y suspendido el Servicio Militar Obligatorio, es preciso una norma legal que regule la organización y procedimientos de las reservas movilizables, es decir, de los recursos humanos que podrán ser incorporados a las Fuerzas Armadas para alcanzar los efectivos totales de las unidades de las fuerzas permanentes, así como para la reposición de bajas, o para cubrir necesidades específicas puntuales que pudieran originarse. Este concepto de reservas movilizables no debe confundirse con una movilización general, que se referiría a la posibilidad, poco probable, de tener que generar nuevas fuerzas y a la obligatoriedad de un alistamiento generalizado en circunstancias excepcionales.

La movilización tiene como objetivos inmediatos y sucesivos:

- Completar las unidades de la Fuerza Permanente.

- Activar las unidades de la Reserva Movilizable. 
- Generar fuerzas adicionales en situaciones extremas.

En consecuencia, uno de los aspectos que considera la nueva Ley del Régimen del Personal Militar de las Fuerzas Armadas es el del tiempo que permanecerán en la situación de reserva, disponible para ser nuevamente llamado en caso de necesidad, aquellos que hubieran finalizado el compromiso que voluntariamente suscribieron con los Ejércitos. Esta obligación afectará a militares de carrera, a los de complemento, y a la tropa profesional.

Indudablemente, este es un aspecto que debe quedar claramente establecido y regulado, ya que no puede excluirse el planteamiento de que aquellos que voluntariamente han decidido comprometerse y servir a las Fuerzas Armadas por un tiempo determinado, o durante toda su vida activa, no contemplen la posibilidad de que puedan ser llamados a ellas posteriormente, antes, por supuesto, que el resto de la sociedad que no adquirió vínculo alguno con las Fuerzas Armadas.

Además, la nueva Ley establece un nuevo tipo de reservista, el reservista voluntario, que se corresponde con los españoles que opten voluntariamente a las plazas que al efecto se convoquen, resulten seleccionados y finalicen un período de formación para adquirir tal condición.

Para casos extremos se contempla también la posibilidad de que el Gobierno solicite del Congreso de los Diputados autorización para la declaración general de reservistas obligatorios que podrá afectar a todos los españoles que en ese año cumplan desde diecinueve a veinticinco años de edad.

Otra consecuencia, por tanto, del nuevo modelo es la necesidad de establecer sistemas y programas de movilización que se ajusten a la futura Ley y normas que la desarrollen..

\section{Personal civil}

Como consecuencia de la restauración que se derivó del Plan NORTE y de la reducción del total de efectivos de tropa que conlleva la adopción del nuevo modelo de Fuerzas Armadas, del Ejército de Tierra precisa de mayor número de personal civil que el que actualmente dispone. Además, la cualificación de una parte importante de ese personal y la ubicación de su puesto de trabajo no son adecuadas a los nuevos requerimientos. 


\section{Algunas consideraciones al proceso de transición}

Dar solución a este problema implicaría tres líneas de actuación: cambiar de puesto de trabajo a unos, reciclar a otros para que obtengan la cualificación precisa para desempeñar sus nuevos cometidos y, por último, contratar nuevo personal.

Este proceso no es fácil debido a las dificultades que suponen los cambios forzosos de destino del personal civil y las restricciones existentes en cuanto a oferta de empleo público se refiere. Por ello se estima oportuno recurrir, cuando sea posible, a la contrata de servicios, fundamentalmente en tareas de mantenimiento y apoyo de instalaciones.

Tras este somero repaso a algunos de los problemas más importantes que el proceso de transición al nuevo modelo de Fuerzas Armadas plantea desde el punto de vista del recurso humano, puede concluirse que si el Plan NORTE ha supuesto para el Ejército de Tierra modificar trascendentalmente su organización, estructura y métodos de planeamiento y gestión, la plena profesionalización de la tropa exige una revolución de mentalidades y actitudes en todos los niveles de mando. Además, cuando la implantación del nuevo modelo finalice, según está previsto, en el año 2.003 se habrá producido también en el conjunto de la sociedad española un cambio de enorme alcance que tendrá consecuencias no sólo de orden político y social, sino también de carácter familiar, laboral y educativo.. Entre otras consideraciones, habrá pasado a la historia un servicio militar que durante decenios ha formado parte del paisaje nacional y ha sido punto de referencia en las vidas de muchas generaciones de jóvenes. 